Vol 11, Issue 5, 2018

\title{
MEAN CENTERING OF RATIO SPECTRA METHOD FOR THE ANALYSIS OF THEOPHYLLINE AND EPHEDRINE HCL MIXTURE IN TABLET
}

\author{
MUCHLISYAM*, SUDARMI, CINDY CAROLINE \\ Department of Chemistry, Faculty of Pharmacy, Universitas Sumatera Utara, Padang Bulan, Medan, 20155, Indonesia. \\ Email: muchlisyam@usu.ac.id
}

Received: 20 December 2017, Revised and Accepted: 27 January 2018

\section{ABSTRACT}

Objective: Mean centering of ratio spectra method (MCR method) is one of the simplest methods for the determination of drug mixtures. The purpose of this research is to determine the content of theophylline (THEO) and ephedrine $\mathrm{HCl}$ (EPH) in tablets by MCR spectra method.

Methods: This research was conducted with the MCR method. It was measured at $271 \mathrm{~nm}$ for THEO and $257 \mathrm{~nm}$ for EPH using $0.1 \mathrm{~N}$ HCL as a solution. The calculation was conducted with Matlab application. The analytical characteristics of the method are detection limit, accuracy, precision, and selectivity. Standard addition method was used to increase the concentration of EPH in the sample until it reached the range of calibration concentration.

Result: The research has showed that validations for THEO were $100.57 \%$ for accuracy, $0.68 \%$ for relative standard deviation (RSD), $0.46 \mu \mathrm{g} / \mathrm{mL}$ for limit of detection (LOD), and $1.52 \mu \mathrm{g} / \mathrm{mL}$ for limit of quantification (LOQ). Meanwhile, the validations for EPH are $100.02 \%$ for accuracy, $0.07 \%$ for RSD, $43.12 \mu \mathrm{g} / \mathrm{mL}$ for LOD, and $143.72 \mu \mathrm{g} / \mathrm{mL}$ for LOQ. The level of THEO is $97.43 \pm 0.17 \%$ and the level of EPH is $101.36 \pm 0.25 \%$ for brand one's tablet. Meanwhile, brand two's tablet contains $98.72 \pm 0.14 \%$ of THEO and $103.62 \pm 0.23 \%$ of EPH.

Conclusion: MCR ultraviolet spectrophotometric method can be used to determine the content of THEO and EPH in tablets and meets the detection limit, accuracy, precision, and selectivity.

Keywords: Theophylline, Ephedrine HCl, Spectrophotometric, Mean Centering of Ratio Spectra, Validation.

(C) 2018 The Authors. Published by Innovare Academic Sciences Pvt Ltd. This is an open access article under the CC BY license (http://creativecommons. org/licenses/by/4. 0/) DOI: http://dx.doi.org/10.22159/ajpcr.2018.v11i5.24365

\section{INTRODUCTION}

Treatment of bronchial asthma always combines two types of active drugs that are mutually reinforcing which aims to accelerate the decrease of shortness of breath of the patient. Theophylline (THEO) and ephedrine $\mathrm{HCl}(\mathrm{EPH})$ are the combination of two active drugs in a tablet dosage form for bronchial asthma. The combination of THEO with chemical name is 1.3-dimethyl-7H-purine-2.6-dione and EPH with chemical name is $(1 \mathrm{R}, 2 \mathrm{~S})-2$-(methylamino)-1-phenylpropan-1-ol $\mathrm{HCl}$ are used to relieve the symptoms of respiratory disorders such as bronchial asthma, bronchial spasms, and allergic [1]. THEO is a bronchodilator for direct relaxation of broncheoli's simple muscle. Meanwhile, EPH is $\alpha$ - and $\beta$-adrenoceptor which is used as a bronchodilator and decongestants [2]. The chemicals structure can be seen in Fig 1a and 1b.

Spectrophotometric methods are used for compounds that have absorption in certain solvents and wavelengths. In the ultraviolet (UV) spectrophotometric methods, EPH has three maximum absorption wavelengths at $263 \mathrm{~nm}, 257 \mathrm{~nm}$, and $251 \mathrm{~nm}$, and THEO has one maximum wavelength which is $270 \mathrm{~nm}$ in acid solvent [3].

Various studies have been published for the simultaneous determination of two or more components in a pharmaceutical combined dosage form by instrument method among others clindamycin, metronidazole, and clotrimazole in reverse-phase high-performance liquid chromatography method; vilanterol and fluticasone furoate by simultaneous equation method and a first-order derivative spectrophotometric method; atovaquone and proguanil by spectrophotometric derivatives methods; and duloxetine hydrochloride and methylcobalamin with the HPTLC method [4-7]. Some researchers have determined THEO and EPH in tablets using derivative ratio spectrum method, HPLC, and zerocrossing derivative [8-10].
Mean centering of ratio spectra (MCR) is one of the development spectrophotometric methods for quantitative analysis of binary or ternary mixtures, which does not need any derivatization steps. This method is known as a cost- and time-effective method rather than chromatography method. It is also more selective than dual wavelength method and other spectrophotometry method [7]. Some researchers have shown MCR can be used to determine for binary mixtures or tertiary mixtures in the complex sample which matrix is unknown [11-15].

The requirement levels for THEO are not $<97 \%$ and not more than $102 \%$ from the levels which are written in the etiquette. Meanwhile, the requirement levels for $\mathrm{EPH}$ are not $<92.5 \%$ and not more than $107.5 \%$ from the levels which are written in the etiquette $[16,17]$.

The determination of mixture using MCR method must meet the validation requirements which are accuracy, precision, selectivity, limit of detection (LOD), and limit of quantification (LOQ) based in ICH guidelines [16].

According to that reason, the aim of this work is to determine the THEO and EPH mixtures in a tablet dosage form of a local product using MCR UV spectrophotometry method.

\section{MATERIALS AND METHODS}

\section{Instrumentations and softwares}

The spectrophotometric analysis of THEO and EPH was conducted with Shimadzu model 1800 double beam spectrophotometer with a spectral bandwidth of $1 \mathrm{~nm}$. Wavelength accuracy of $0.1 \mathrm{~nm}$ (at $656.1 \mathrm{~nm} \mathrm{D2}$ ) was used to measure the absorbance of all the solutions. Softwares were used in the study were spectra automatically obtained by UV 
<smiles>CNC(C)[C@H](O)c1ccccc1</smiles>

Fig. 1: (a) Structure of theophylline [3], (b) structure of ephedrine $\mathrm{HCl}$ [3]

Probe system software, MATLAB version 9.0. Digital scale (Boeco), sonicator (Branson 1510), and the other instrument are used in sample preparations.

\section{Materials}

Pharmaceutical grades of THEO and EPH were from Food and Drug Regulatory Agency of Indonesia (claimed purity of 100.31\%). $\mathrm{HCl} 37 \%$ were purchased from Merck Ltd., Rudang, Medan, Indonesia. Indonesia's pharmaceutical product contained $130 \mathrm{mg}$ of THEO and $10 \mathrm{mg}$ of EPH per tablet was manufactured by PT Graha Farma Tangerang, Indonesia.

\section{Procedures of experiment}

Determination of THEO and EPH mixtures with MCR method was conducted by following steps [13-15].

\section{Preparation of THEO standard solution}

Carefully weighed of $50 \mathrm{mg}$ THEO and then transferred it to a $50 \mathrm{~mL}$ volumetric flask dissolved it in $0.1 \mathrm{~N} \mathrm{HCl}$ by adding it to the line. Standard stock solution concentration was $1000 \mu \mathrm{g} / \mathrm{mL}$ (stock solution). $5 \mathrm{~mL}$ of parent solution transferred to a $50 \mathrm{~mL}$ volumetric flask diluted it using $0.1 \mathrm{~N} \mathrm{HCl}$ by adding it to the line, and the concentration would be $100 \mu \mathrm{g} / \mathrm{mL}$.

\section{Preparation of EPH standard solution}

Carefully weighed $100 \mathrm{mg}$ of EPH and then transferred to a $100 \mathrm{~mL}$ volumetric flask dissolved it in $0.1 \mathrm{~N} \mathrm{HCl}$ and added the $0.1 \mathrm{~N} \mathrm{HCl}$ to the line. Standard solution concentration was $1000 \mu \mathrm{g} / \mathrm{mL}$ (stock solution).

\section{Spectral characteristic of THEO and EPH}

The absorption spectrum of UV spectrophotometry is one of the characteristics of the analysis of a drug [3]. Meanwhile, other characteristics are solubility and qualitative identification with color reactions. In the analysis of THEO and EPH mixtures, an examination of the absorption spectrum is conducted by developing the maximum wavelength which is the start of the MCR methods.

\section{Construction spectra absorption curve of THEO}

Pipetted of $2 \mathrm{~mL}$ THEO standard working solution (concentration $=100 \mu \mathrm{g} / \mathrm{mL}$ ), then transferred to a $25 \mathrm{~mL}$ volumetric flask. Diluted it using $0.1 \mathrm{~N} \mathrm{HCl}$ to the line of volumetric flask, then homogenized to get the concentration of $8 \mu \mathrm{g} / \mathrm{mL}$ and measured the absorbance from $200 \mathrm{~nm}$ to $400 \mathrm{~nm}$.

\section{Construction spectra absorption curve of EPH}

Pipetted of $9 \mathrm{~mL}$ EPH parent solution and then transferred to a $25 \mathrm{~mL}$ volumetric flask. Diluted it using $0.1 \mathrm{~N} \mathrm{HCl}$ to the line of volumetric flask, then homogenized to get the concentration of $360 \mu \mathrm{g} / \mathrm{mL}$ and measured the absorbance from $200 \mathrm{~nm}$ to $400 \mathrm{~nm}$.
Construction of spectral characteristics of THEO and EPH in mixture

Pipetted $2 \mathrm{~mL}$ THEO working solutions and pipetted $9 \mathrm{~mL}$ from EPH stock solutions, then transferred into $25 \mathrm{~mL}$ volumetric flask. Diluted it using $0.1 \mathrm{~N} \mathrm{HCl}$ until the line of volumetric flask, then homogenized to get the concentration $8 \mu \mathrm{g} / \mathrm{mL}$ of THEO and $360 \mu \mathrm{g} / \mathrm{mL}$ of EPH and measured the absorbance from $200 \mathrm{~nm}$ to $400 \mathrm{~nm}$.

\section{Construction of absorbance spectrum mixture of THEO and EPH}

Pipetted $1.0 \mathrm{~mL}, 1.5 \mathrm{~mL}, 2.0 \mathrm{~mL}, 2.5 \mathrm{~mL}$, and $3.0 \mathrm{~mL}$ THEO working solutions, respectively, then transferred each to different $25 \mathrm{~mL}$ volumetric flasks, then pipetted $4.2 \mathrm{~mL}, 6.3 \mathrm{~mL}, 8.3 \mathrm{~mL}, 10.4 \mathrm{~mL}$, and $12.5 \mathrm{~mL}$ EPH stock solutions and transferred each to the THEO solution above into $50 \mathrm{ml}$ volumetric flask and diluted them using $0.1 \mathrm{~N} \mathrm{HCl}$ to the line of volumetric flask, then homogenized to get their own absorbance.

\section{THEO absorbance with MCR spectra method}

THEO absorbance spectrum was manipulated with UV Probe 2.42 software by dividing $332.99 \mu \mathrm{g} / \mathrm{mL}$ EPH to get the first ratio spectra as data sets. Data sets were printed and exported to Ms. Excel for mean centering with the help of Matlab R2009a.

\section{EPH Absorbance with MCR Spectra Method}

EPH mixtures absorbance spectrum was manipulated with UV Probe 2.42 software by dividing $8.096 \mu \mathrm{g} / \mathrm{mL}$ THEO to get the first ratio spectra as data sets. Data sets were printed and exported to Ms. Excel for mean centering with the help of Matlab R2009a.

\section{Construction of calibration curve}

The calibration curve of UV spectrophotometry on the X-axis represents the wavelength and on the $\mathrm{Y}$-axis represents the absorbance of a spectrum. However, on the MCR method, the Y-axis is the amplitude in the form of the result data after the mean centering with the help of Matlab software. The process is calculated by calculating the result of measurement of the spectrums which are obtained from the distribution of spectral absorbance data which have been analyzed at each wavelength point using UV Probe software 2.42 and obtains absorbance ratio. The calculation by Matlab software results the average value of the absorbance value of the ratio at each wavelength point. The result of this average value is substracted by the absorbance ratio is the MC value and is called the amplitude and plotted by the wavelength and obtains the regression equation [12-14].

\section{Calibration curve of THEO and EPH using MCR spectra method}

Mean centering value (amplitude) from the first ratio spectra at $271 \mathrm{~nm}$ for THEO and $257 \mathrm{~nm}$ for EPH was obtained, then calculated the regression and plotted it in a concentration versus amplitude graph using Matlab R2009a [13].

\section{Validation Test}

Linearity

Standard solution of THEO and EPH for absorption spectrum was made and measured at the selected wavelength points $(271 \mathrm{~nm}$ for THEO and $257 \mathrm{~nm}$ for EPH). The amplitude values of both active substances were determined using the regression equation for each component at its own selected wavelengths. The obtained regression equation general formula is as below [18-20].

$\mathrm{Y}=\mathrm{ax}+\mathrm{b}$

Notes:

$\mathrm{Y}=$ Amplitude

$\mathrm{a}=$ Slope

$\mathrm{x}=$ Concentration $(\mu \mathrm{g} / \mathrm{mL})$

$\mathrm{b}=$ Constant. 
Relative standard deviation (RSD) test

Formula for RSD calculation:

$\mathrm{RSD}=\frac{\mathrm{CD}}{\overline{\mathrm{X}}} \times 100 \%$

Note:

RSD $=$ Relative standard deviation

$\mathrm{SD}=$ Standard deviation

$\overline{\mathrm{X}}=$ Average data.

\section{LOD and LOQ test}

According to the absorbance at analysis wavelength, LOD and LOQ are counted as below.

$\mathrm{SD}=\sqrt{\frac{\sum(\mathrm{Y}-\mathrm{Yi})^{2}}{\mathrm{n}-2}}$

$\mathrm{LOD}=\frac{3.3 \times \mathrm{SD}}{\text { slope }}$

$\mathrm{LOQ}=\frac{10 \times \mathrm{SD}}{\text { slope }}$

Note:

$\mathrm{SD}=$ Standard deviation (residual standard deviation)

Slope $=a(y=a x+b)$

\section{Recovery test}

Recovery test was calculated by measured recovery percentage in three specific points which were: $80 \%, 100 \%$, and $120 \%$. In each of the specific points, the test used $70 \%$ from the sample and $30 \%$ from the pure active substances (standard addition method).

In standard addition method by adding purify active substances, the number of samples analyzed with the necessary concentration of the analytes. Differences from the results were compared with theoretical concentration. In that method, the levels of substances were obtained as the ratio of the obtained results to the theoretical results [18.20]:

$$
\% \mathrm{R}=\frac{\mathrm{Ca}-\mathrm{Cb}}{\mathrm{Cc}} \times 100 \%
$$

Note:

$\% \mathrm{R}=$ Percentage of recovery

$\mathrm{C}=$ Concentration after addition

$\mathrm{C}_{\mathrm{c}}=$ THEO concentration before addition

$\mathrm{C}_{\mathrm{b}}=$ Concentration of the standard substances added.

\section{Procedures}

Weighed powdered samples equivalent to $10 \mathrm{mg}$ of THEO (counted the equivalency of EPH) and $226 \mathrm{mg}$ of EPH standard substance. The powdered substances were transferred to a $25 \mathrm{~mL}$ volumetric flask, added with $15 \mathrm{~mL}$ of $0.1 \mathrm{~N} \mathrm{HCl}$, sonicated for 15 minutes, and added the solvent to the line of volumetric flask. Homogenized it and pipetted $0.55 \mathrm{~mL}$ from the prepared solution, transferred it to a $25 \mathrm{~mL}$ of volumetric flask, and added the $0.1 \mathrm{HCl}$ to the line of volumetric flask. Purified EPH was added after sample and transferred to the volumetric flask. These procedures were repeated 3 times from each of the selective point and counted the recovery percentages

\section{Construction solution for the determination of THEO and EPH in} tablet

A total of 20 tablets of brand's tablet which contained $130 \mathrm{mg}$ of THEO and $10 \mathrm{mg}$ of EPH were powdered and mixed them well separately. Accurately weighed the amount of the powdered tablets equivalent to $50 \mathrm{mg}$ of THEO (repeated the procedure 6 times) and counted the equivalent amount of $\mathrm{EPH}$, then transferred them to a $100 \mathrm{~mL}$ volumetric flasks and $50 \mathrm{~mL}$ of $0.1 \mathrm{~N} \mathrm{HCl}$ was added. The prepared solution was sonicated for 15 minutes and then added the $0.1 \mathrm{~N} \mathrm{HCl}$ to the line of volumetric flasks and homogenized. The prepared solution was filtered, and the first $10 \mathrm{~mL}$ filtrate was discarded. From the next filtrate, pipetted $0.4 \mathrm{~mL}$ and transferred to a $25 \mathrm{~mL}$ volumetric flask.

Standard addition method was conducted by adding $7.1 \mathrm{~mL}$ from EPH stock solution (concentration $=1000 \mu \mathrm{g} / \mathrm{mL}$ ) and transferred it to the volumetric flask that contained $0.4 \mathrm{~mL}$ of prepared solution. This mixture was diluted using $0.1 \mathrm{~N} \mathrm{HCL}$ to the line of the volumetric flask which contained $8 \mu \mathrm{g} / \mathrm{mL}$ of THEO and $285 \mu \mathrm{g} / \mathrm{ml}$ of EPH.

The final prepared solution was measured, manipulated by dividing $8.096 \mu \mathrm{g} / \mathrm{mL}$ THEO, and $332.996 \mu \mathrm{g} / \mathrm{ml}$ EPH for mean centering to count the concentration.

\section{Determination of THEO and EPH in tablet}

The obtained amplitude from the analysis was substituted to the regression equation (linearity) to determine the levels of the analytes (THEO and EPH) in the sample. Percentage of the analytes in one tablet can be counted using these formulas [19]:

$\mathrm{C}=\mathrm{X} \times \mathrm{FP} \times \mathrm{V}$

$$
\begin{aligned}
& \mathrm{AL}=\frac{\mathrm{C}(\mathrm{mg})}{\mathrm{W}} \times \frac{\mathrm{TW}}{20} \\
& \% \mathrm{~A}=\frac{\mathrm{AL}}{\mathrm{EL}} \times \% \text { purity }
\end{aligned}
$$

Note:

$\mathrm{C}=$ Content of substance

$\mathrm{X}=$ Concentration of e in the sample

FP $=$ Dilution factor

$\mathrm{V}=$ Volume of volumetric flask used for the prepared solution

$\mathrm{AL}=$ Acquisition level

$\mathrm{W}=$ Weight of the powder

TW=Total weight of 20 tablets

$\% \mathrm{~A}=$ Percentage of analytes

EL=Etiquettes level

\section{Analysis data statistically}

The obtained data of THEO and EPH were analyzed statistically using table t-test. The formula is [19]:

$\mathrm{SD}=\sqrt{\frac{\sum(\mathrm{X}-\overline{\mathrm{X}})^{2}}{\mathrm{n}-2}}$

t-statistic $=\frac{x-\bar{x}}{\mathrm{SD} / \sqrt{\mathrm{n}}}$

To obtain the t-statistic, the formula is:

Data are taken when $t_{\text {statistic }}$ less than $t_{\text {table }}$ in confidence interval of $95 \%$ and the value of alpha is $0.05 \%$.

Note

$\mathrm{SD}=$ Standard deviation

$\mathrm{Xi}=$ Data that used

$\overline{\mathrm{X}}=$ Average data

$\mathrm{n}=$ Repeatable value

$\alpha=$ Confidence level.

To count the actual levels of THEO and EPH in a sample statistically, we can use this formula [19]: 
$1 / \overline{\mathrm{x}} \pm \mathrm{t}_{\text {table }} \times \frac{\mathrm{SD}}{\sqrt{\mathrm{n}}}$

Note:

$\overline{\mathrm{X}}=$ Average data

$\mathrm{t}=\mathrm{t}$-table value.

\section{RESULTS AND DISCUSSIONS}

In MCR spectra method, the primary requirement for analysis is that the entire spectra should follow the Beer's law that the wavelength for $8.96 \mu \mathrm{g} / \mathrm{ml}$ THEO at $271 \mathrm{~nm}$ and for $361.08 \mu \mathrm{g} / \mathrm{ml} \mathrm{EPH}$ is $262 \mathrm{~nm}$, $257 \mathrm{~nm}$, and $252 \mathrm{~nm}$.

Based on Figs. 2-4, it can be seen that the results of the absorption measurements of the samples are within the range of Lambert-Beer law and these correspond to the literature which states that wavelength of THEO in acid solvent $\left(\mathrm{A}_{1}^{1}=536 \mathrm{a}\right)$ is at $270 \mathrm{~nm}$, meanwhile for EPH $\left(\mathrm{A}^{1}=12 \mathrm{a}\right)$ in acid solvent is $263 \mathrm{~nm}, 257 \mathrm{~nm}$, and $251 \mathrm{~nm} \mathrm{[3].}$

Based on the theory, the differences wavelengths of each THEO and EPH are not less and not $>2 \mathrm{~nm}$ [3]. In this case, the wavelengths of each component are qualified.

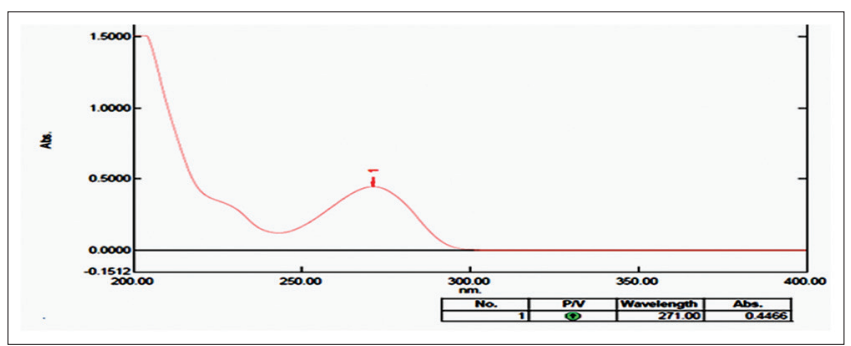

Fig. 2: Spectrum characteristic of $8.96 \mu \mathrm{g} / \mathrm{mL}$ theophylline

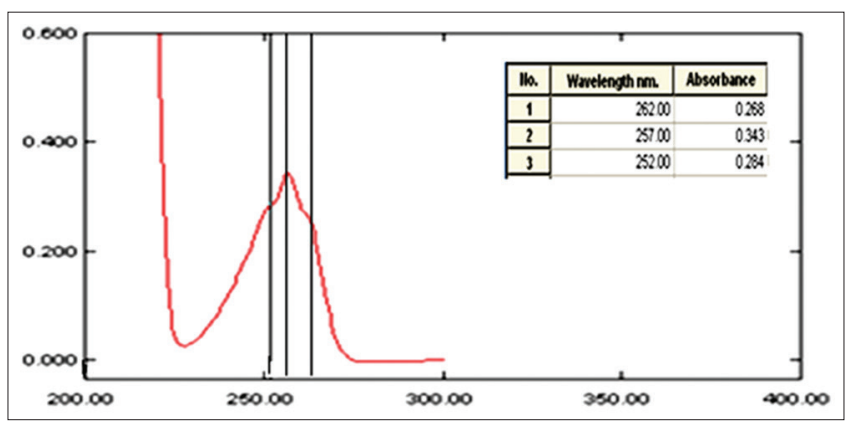

Fig. 3: Spectrum characteristics of $361.08 \mu \mathrm{g} / \mathrm{mL}$ ephedrine $\mathrm{HCl}$

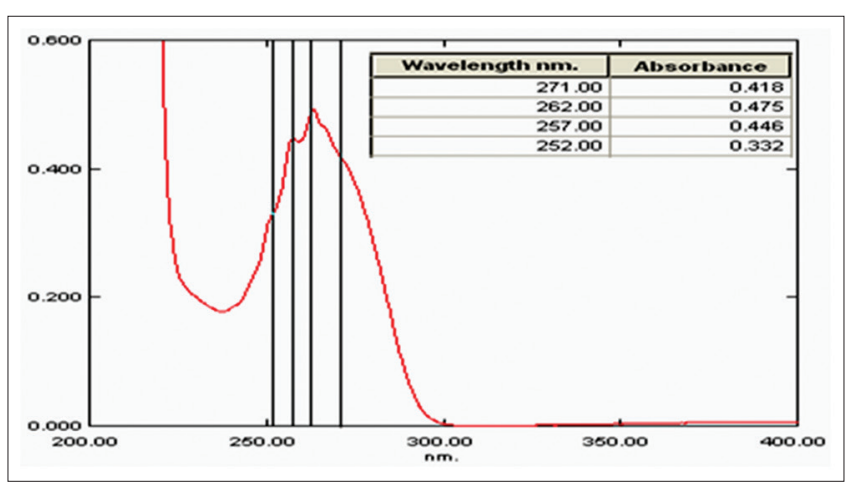

Fig. 4: Spectrum characteristics of $8.96 \mu \mathrm{g} / \mathrm{mL}$ theophylline and $361.08 \mu \mathrm{g} / \mathrm{mL}$ ephedrine $\mathrm{HCl}$ in mixture
Selectivity of wavelength and divisor

In MCR spectrophotometric method, the selectivity of wavelength affects the results of the calculation of the levels of active compound contained in a pharmaceutical preparation. Based on the results, the selective wavelength for THEO and EPH is $224-400 \mathrm{~nm}$.

The reason to take $224-400 \mathrm{~nm}$ wavelengths is the absorption would increase until they reach the absorbance above 0.8 , the wavelengths from $200 \mathrm{~nm}$ to $223 \mathrm{~nm}$. Therefore, it can be abandoned or not included to prevent the affection in determination.

Divisor is also the important factor which can affect the calculation in determine the level of substance. Selection of divisors was based on the ratio of active substances in the sample to the other one after the standard addition method was conducted.

Divisors were chosen based on the ratio 1:41 which were $8.096 \mu \mathrm{g} / \mathrm{mL}$ as the divisor of THEO and $332.996 \mu \mathrm{g} / \mathrm{mL}$ as the divisor of EPH. The divisor was better in the range concentration of calibration and near the absorbance of 0.4343 to reduce miscalculation Figs. 5 and 6 .

Results of absorption spectrum before and after the addition of EPH standard

THEO mixed content should be added with EPH standard method addition because the comparison of THEO and EPH in medication so large which was 13:1. To meet the Lambert-Beer law, the concentration of EPH had been added to $332.996 \mu \mathrm{g} / \mathrm{mL}$ when the THEO concentration was $8.096 \mu \mathrm{g} / \mathrm{mL}$. By addition of EPH standard, the concentration ratio changed to $1: 41$. The results can be seen on the Figs. 7 and 8.

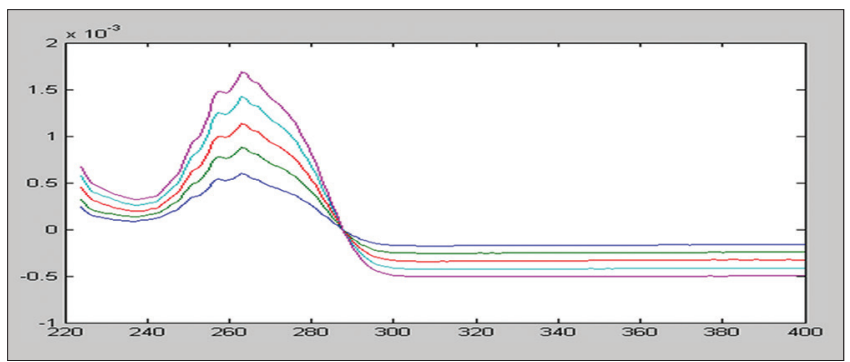

Fig. 5: Spectra ratio of theophylline using $332.996 \mu \mathrm{g} / \mathrm{mL}$ ephedrine $\mathrm{HCl}$ as divisor

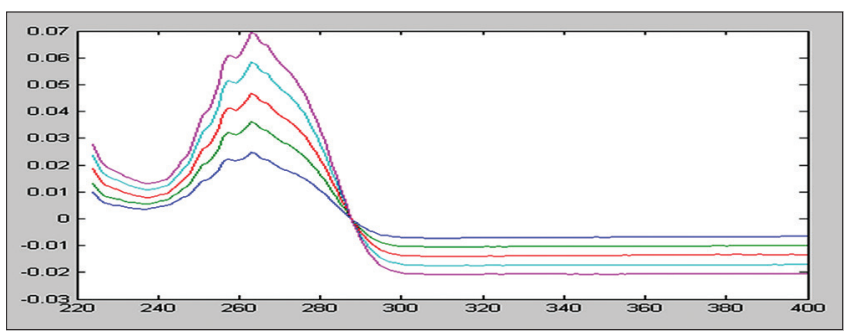

Fig. 6: Spectra ratio of ephedrine $\mathrm{HCl}$ using $8.096 \mu \mathrm{g} / \mathrm{mL}$ theophylline as a divisor

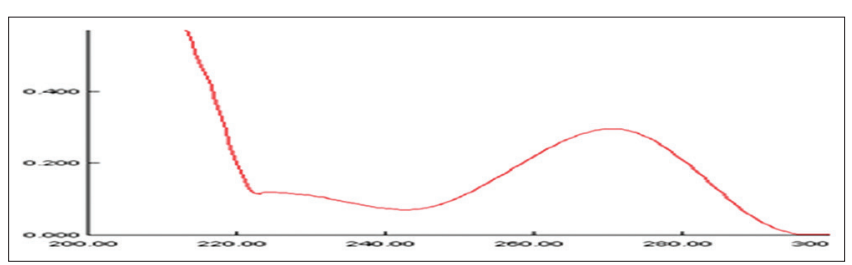

Fig. 7: Absorption spectrum of theophylline and ephedrine $\mathrm{HCl}$ mixture (before standard addition method) 
Figs. 7 and 8 show that there is a difference of the spectrum before and after the addition of EPH standard. Before the addition of EPH standard, the spectrum that can only be seen was THEO spectrum, meanwhile, EPH spectrum cannot be seen.

Hence, the determination of EPH in tablet dosage form could not be done because its concentration in the mixture was very low. By addition of EPH, its spectrum could be seen. This means that the MCR method for assaying this mixture should be done by adding standard EPH solution.

\section{THEO and EPH calibration curve}

Calibration curve in MCR method is constructed by concentrations versus amplitude (mean centering results) graph. Regression equation that obtained using MCR method for THEO is $\mathrm{Y}=0.000117 \mathrm{X}-0.000013$ and for $\mathrm{EPH}$ is $\mathrm{Y}=0.000121 \mathrm{X}+0.001065$

Figs. 9 and 10 show that the correlation coefficient (r) of THEO is 0.9991 and EPH is 0.9993 . The value of correlation coefficient which is $>0.97$ shows that there is a linear correlation between concentration and amplitude [19].

\section{Results of validation test}

The result of validation test with measurement of accuracy, precision, LOD, and LOQ can be seen in Table 1.

Table 1 summarizes that the average of recovery percentage is on the range of $80-120 \%$. It means that the method is accurate for the determination of THEO and EPH and the value of precision for analytes with 0.68 and $0.07 \%$ is not $>2 \%$.

The result shows that this method has a great precision. All of the measurements' results were greater than LOD and LOQ. Concentration of LOQ is the minimum concentration of a substance to obtain the quantitative amplitude [17]. This means that MCR methods for the determination of THEO and EPH mixture in tablet have met the requirements of validation methods.

\section{Determination of THEO and EPH in sample tablet}

Determination of THEO and EPH was conducted by the MCR method. Concentration of THEO and EPH in the samples could be determined from their own regression equation and must be in the range of calibration curve. Standard addition method and dilution could be conducted to meet the conditions above.

Dilution factor in this determination of tablet dosage forms was 45.45 times. The results of THEO and EPH levels in the samples can be seen in Tables 2 and 3.
Requirement levels of THEO in a tablet dosage form according to Indonesian pharmacopeia fif $^{\text {th }}$ edition are $97-102 \%$ [14,15]. The research shows that the brand one tablet contains $97.43 \pm 0.17 \%$ and the brand two tablet contains $98.72 \pm 0.14 \%$. Meanwhile, requirement levels of EPH in a tablet dosage form according to Indonesian pharmacopeia fif ${ }^{\text {th }}$ edition 2014 are $92.5-107.5 \%$. The research shows that the brand one tablet contains $101.36 \pm 0.25 \%$ and the brand two tablet contains $103.62 \pm 0.23 \%$

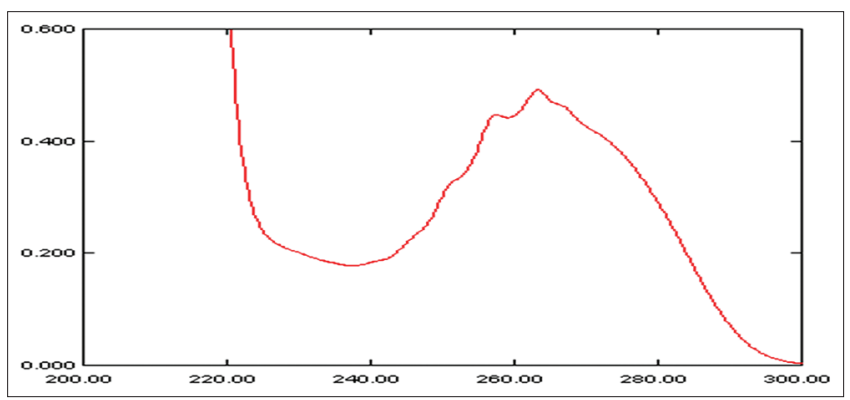

Fig. 8: Absorption spectrum of theophylline and ephedrine $\mathrm{HCl}$ mixture (after standard addition method)

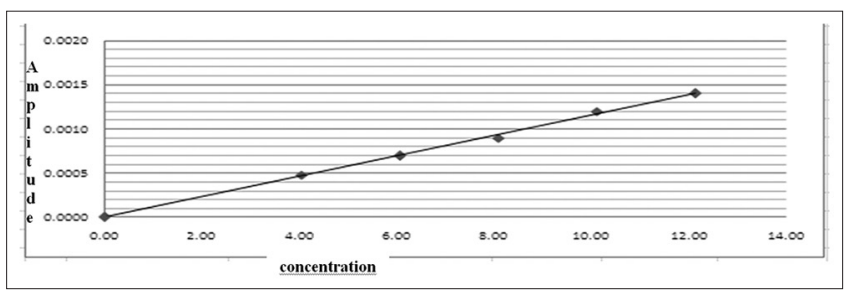

Fig. 9: Calibration curve of theophylline

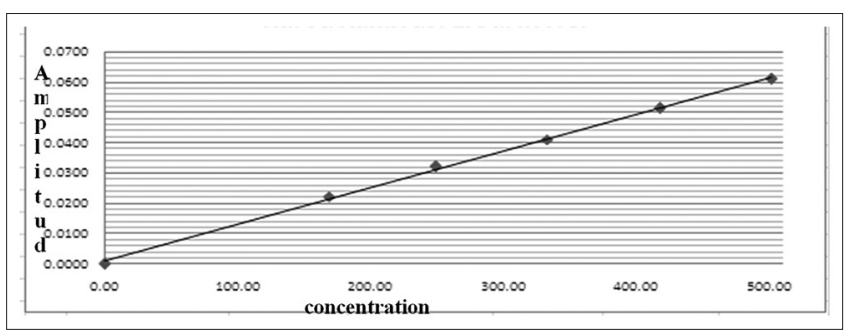

Fig. 10: Calibration curve of ephedrine $\mathrm{HCl}$

Table 1: Validation test of THEO and EPH

\begin{tabular}{llllll}
\hline No. & Active substance & Accuracy $\%$ & Precision $\mathbf{~}$ & LOD $\boldsymbol{\mu g} / \mathbf{m L}$ & LOQ $\boldsymbol{\mu g} / \mathbf{m L}$ \\
\hline 1 & THEO & 100.57 & 0.68 & 0.46 & 1.52 \\
2 & EPH & 100.02 & 0.07 & 43.12 & 143.72 \\
\hline
\end{tabular}

THEO: Theophylline, EPH: Ephedrine HCl, LOD: Limit of detection, LOQ: Limit of quantification

Table 2: THEO and EPH levels in brand's one tablet

\begin{tabular}{lllll}
\hline No. & Active substances & Brand tablet (\%) & Content in the etiquette & Content requirement (\%) \\
\hline 1 & THEO & $(97.43 \pm 0.17)$ & $130 \mathrm{mg}$ & $97-102$ \\
2 & EPH & $(101.36 \pm 0.25)$ & $10 \mathrm{mg}$ & $92.5-107.5$ \\
\hline
\end{tabular}

THEO: Theophylline, EPH: Ephedrine $\mathrm{HCl}$

Table 3: THEO and EPH levels in brand's two tablet

\begin{tabular}{lllll}
\hline No. & Active substances & Brand tablet (\%) & Content in the etiquette & Content requirement (\%) \\
\hline 1 & THEO & $(98.72 \pm 0.14)$ & $130 \mathrm{mg}$ & $97-102$ \\
2 & EPH & $(103.62 \pm 0.23)$ & $10 \mathrm{mg}$ & $92.5-107.5$ \\
\hline
\end{tabular}

THEO: Theophylline, EPH: Ephedrine HCl 
In conclusion, the content of THEO and EPH in the brands tablet meets the requirements.

\section{CONCLUSION}

MCR UV spectrophotometry method can be used for the determination of THEO and EPH in tablet dosage form with standard addition methods and meets the parameters of analytical characteristic of the method.

\section{CONFLICT OF INTEREST}

We declare that there is no conflict of interest.

\section{REFERENCES}

1. Charles E, Sims MD, Do Pico GA. Bronchodilator effect of ephedrine and theophylline after two to four weeks of repeated dosing. J Pub 1978;73:1019-20.

2. Siswandono S, Soekardjo B. Medicinal Chemistry 2. Surabaya: Airlangga University Press; 1995. p. 400-2.

3. Moffat AC, Osselton MD, Widdop B. Clarke's Analysis of Drug and Poisons. $3^{\text {rd }}$ ed. London: Pharmaceutical Press; 2005. p. 517, 2138-9, 1337-8.

4. Masimukku SK, Chintala R. Development and validation of spectrophotometric methods for simultaneous estimation of vilanterol and fluticasone furoate in pharmaceutical formulations. Asian J Pharm Clin Res 2017;10:302-5.

5. Ponnuri RN, Pragallapat P, Sk MN, Mandavaa BV, Sudha BS, Prasad KB. Development and validation of a stability indicating reverse phase-high performance liquid chromatography method for simultaneous determination of clindamycin, metronidazole, and clotrimazole in pharmaceutical combined dosage forms. Asian J Pharm Clin Res 2017;10:111-7.

6. Vijay DC, Nejal MB, Mallika S, Pranav SS. Comparative evaluation of first order, absorbance ratio and bivariate spectrophotometric methods for determination of atovaquone and proguanil in pharmaceutical formulation Malarone. Int J Pharm Pharm Sci 2015;7:165-71.

7. Seema S, Bhavesh P. Implementation of Qbd approach to develop and validate analytical method for simultaneous estimation of duloxetine hydrochloride and methylcobalamin in pharmaceutical dosage form by
HPTLC method. Int J Pharm Pharm Sci 2016;8:105-17.

8. Senturk Z, Erk N, Ozkan SA, Akay C, Cevheroglu S. Determination of theophylline and ephedrine $\mathrm{HCl}$ in tablets by ratio-spectra derivative spectrophotometry and LC. J Pharm Bio Analy 2002;29:291-8.

9. Pratiwi P. Optimization of Mobile Phase Methanol and Flow Rate in Determinaton of Theophylline and Ephedrine $\mathrm{HCl}$ Mixture into Tablets with High Performance Liquid Chromatography (HPLC), Thesis. Medan: North Sumatera University; 2011. p. 20.

10. Tarigan OT. Determination of Theophylline and Ephedrine $\mathrm{HCl}$ in Tablet Dosage Form using Derivative Spectrophotometric Method, Thesis. Medan: North Sumatera University; 2015. p. 30-47.

11. Nada SA, Badr AE, Salwa IT. Two spectrophotometric methods for simultaneous determination of some antihyperlipidemic drugs. J Pharm Analy 2012;2:279-84.

12. Afkhami A, Bahram M. Mean centering of ratio spectra as a new spectrophotometric method for the analysis of binary and ternary mixtures. Talanta 2005;66:712-20.

13. Rajni R, Usha G. Mean centering of ratio spectra as a new spectrophotometric method for the analysis of binary mixtures of vanadium and lead in water samples and alloys. Res J Chem Sci 2012;2:22-9.

14. Kamal, AH, El-Malla SF, Hammad, SF. A review on spectrophotometric methods for simultaneous multicomponent analysis. Eur J Pharm Med Res 2016;3:348-60.

15. Lofty HM, Amer SM, Zaazaa H, Mostafa NS. Spectrophotometric method for quantitative determination of binary mixture of naproxen sodium and domperidone maleate. Austin J Anal Pharm Chem 2015;2:1044.

16. Ditjen PO. Indonesian Pharmacopeia. $5^{\text {th }}$ ed. Jakarta: Indonesian Health Ministry; 2014. p. 363-4, 1250-1.

17. Ditjen PO. Indonesian Pharmacopeia. $3^{\text {rd }}$ ed. Jakarta: Indonesian Health Department; 1979. p. 53.

18. Harmita F. Implementation Guidelines and the Calculation Method Validation, Jakarta: Pharmaceutial Science Magazine; 2004. p. 118-20.

19. Sudjana E. Statistic Method. Bandung: Tartiso Press; 2005. p. 93, 145, 201, 225.

20. Ermer J, Miller JH. Method Validation in Pharmaceutical Analysis. A Guide to Best Practice. Weinheim: Wiley-Vch Verlag GmBH \& Co. KGaA; 2005. p. 171. 